\title{
Pseudarthrosis rate following anterior cervical discectomy with fusion using an allograft cellular bone matrix: a multi-institutional analysis
}

\author{
*Stephen M. Bergin, MD, PhD, Timothy Y. Wang, MD, Christine Park, BS, \\ Shashank Rajkumar, BS, C. Rory Goodwin, MD, PhD, Isaac O. Karikari, MD, \\ Muhammad M. Abd-El-Barr, MD, PhD, Christopher I. Shaffrey, MD, Chester K. Yarbrough, MD, \\ and Khoi D. Than, MD
}

Department of Neurological Surgery, Division of Spine, Duke University, Durham, North Carolina

\begin{abstract}
OBJECTIVE The use of osteobiologics, engineered materials designed to promote bone healing by enhancing bone growth, is becoming increasingly common for spinal fusion procedures, but the efficacy of some of these products is unclear. The authors performed a retrospective, multi-institutional study to investigate the clinical and radiographic characteristics of patients undergoing single-level anterior cervical discectomy with fusion performed using the osteobiologic agent Osteocel, an allograft mesenchymal stem cell matrix.

METHODS The medical records across 3 medical centers and 12 spine surgeons were retrospectively queried for patients undergoing single-level anterior cervical discectomy and fusion (ACDF) with the use of Osteocel. Pseudarthrosis was determined based on CT or radiographic imaging of the cervical spine. Patients were determined to have radiographic pseudarthrosis if they met any of the following criteria: 1) lack of bridging bone on CT obtained $>300$ days postoperatively, 2) evidence of instrumentation failure, or 3) motion across the index level as seen on flexion-extension cervical spine radiographs. Univariate and multivariate analyses were then performed to identify independent preoperative or perioperative predictors of pseudarthrosis in this population.

RESULTS A total of 326 patients met the inclusion criteria; $43(13.2 \%)$ patients met criteria for pseudarthrosis, of whom $15(34.9 \%)$ underwent revision surgery. There were no significant differences between patients with and those without pseudarthrosis, respectively, for patient age ( 54.1 vs 53.8 years), sex ( $34.9 \%$ vs $47.4 \%$ male), race, prior cervical spine surgery ( $37.2 \%$ vs $33.6 \%)$, tobacco abuse ( $16.3 \%$ vs $14.5 \%)$, chronic kidney disease $(2.3 \%$ vs $2.8 \%)$, and diabetes $(18.6 \%$ vs $14.5 \%)(p>0.05)$. Presence of osteopenia or osteoporosis $(16.3 \%$ vs $3.5 \%)$ was associated with pseudarthrosis $(p<0.001)$. Implant type was also significantly associated with pseudarthrosis, with a $16.4 \%$ rate of pseudarthrosis for patients with polyetherethereketone (PEEK) implants versus $8.4 \%$ for patients with allograft implants $(p=0.04)$. Average lengths of follow-up were 27.6 and 23.8 months for patients with and those without pseudarthrosis, respectively. Multivariate analysis demonstrated osteopenia or osteoporosis (OR 4.97, 95\% $\mathrm{Cl} 1.51-16.4, \mathrm{p}<0.01)$ and usage of PEEK implant (OR 2.24, 95\% Cl 1.04-4.83, $p=0.04)$ as independent predictors of pseudarthrosis.
\end{abstract}

CONCLUSIONS In patients who underwent single-level ACDF, rates of pseudarthrosis associated with the use of the osteobiologic agent Osteocel are higher than the literature-reported rates associated with the use of alternative osteobiologics. This is especially true when Osteocel is combined with a PEEK implant.

https://thejns.org/doi/abs/10.3171/2021.3.FOCUS2166

KEYWORDS osteobiologic; pseudarthrosis; anterior cervical discectomy and fusion; ACDF

$\mathrm{A}$ NTERIOR cervical discectomy and fusion (ACDF) is the most commonly performed surgery for cervical radiculopathy and myelopathy. ${ }^{1}$ Pseudarthrosis is the failure of bony fusion to occur, and the resulting nonunion is associated with worse clinical outcomes and higher costs, although the exact clinical significance of ra- diographically diagnosed pseudarthrosis remains controversial. 2,3 The etiology of pseudarthrosis following ACDF is multifactorial, and known predictors include multilevel ACDFs, osteoporosis, chronic kidney disease, and smoking status. ${ }^{4}$

Strategies to overcome the risk of pseudarthrosis have

ABBREVIATIONS ACDF = anterior cervical discectomy and fusion; $C B M=$ cellular bone matrix; $D B M=$ demineralized bone matrix; $P E E K=$ polyetherethereketone. SUBMITTED January 30, 2021. ACCEPTED March 17, 2021.

INCLUDE WHEN CITING DOI: 10.3171/2021.3.FOCUS2166.

* S.M.B. and T.Y.W. contributed equally to this work. 
included the adoption of osteobiologics.$^{5,6}$ Osteobiologics are a class of engineered materials designed to promote bone healing by enhancing the osteoconductive, osteoinductive, and osteogenic processes required for bone growth.7 Cellular bone matrices (CBMs) are osteobiologics composed of allograft mesenchymal stem cells as well as osteoprogenitor cells and are meant to mimic the properties of iliac crest autograft without the morbidity associated with harvest. CBMs contain live bone cells, provide a scaffold for new bone formation, and enhance growth signals that direct cells to form new bone. ${ }^{8}$ The cells in CBMs are either undifferentiated mesenchymal stem cells or lineage-committed bone cells, and the use of these live cells may confer an osteogenic advantage over the use of allogenic demineralized bone matrix (DBM) grafts. ${ }^{9,10}$

Osteocel (NuVasive Inc.) is an osteobiologic in current use that comprises human donor allograft mesenchymal cells as well as osteoprogenitor cells. While Osteocel has been used in more than 250,000 ACDF cases globally, data are limited regarding its clinical and radiographic efficacy. One industry-sponsored prospective trial of patients who underwent a single-level ACDF with a polyetherethereketone (PEEK) interbody spacer with Osteocel found a $92 \%$ rate of fusion at 24 months, with no patient undergoing a revision for pseudarthrosis. ${ }^{5}$ However, fusion rates following ACDF with Osteocel and other implant types are unknown. Additionally, there is a lack of non-industry-funded literature to further corroborate the existing literature on Osteocel. In this investigation, to our knowledge the largest study ever on patients receiving Osteocel, we sought to determine rates of clinical and radiographic pseudarthrosis in patients undergoing ACDF using Osteocel combined with either a structural allograft or PEEK implant.

\section{Methods}

Medical records across 3 medical centers and 12 spine surgeons were retrospectively reviewed for patients undergoing single-level ACDF utilizing Osteocel. The data acquisition period ranged from January 2014 through January 2020. Patient data recorded included age, sex, race, BMI, smoking status, osteopenia or osteoporosis, chronic kidney disease, diabetes, and any prior spine surgery, including previous cervical spine surgery. Surgical data included operative levels, blood loss, implant type (i.e., structural allograft or PEEK), and use of an anterior cervical plate. Length of hospitalization, complications requiring admission within 30 days, and emergency department visits within 30 days of surgery were also recorded. Pseudarthrosis was determined based on CT scans or radiographs of the cervical spine. Patients were determined to have radiographic pseudarthrosis if they met any of the following criteria: 1) lack of bridging bone on CT obtained $>300$ days postoperatively, 2) evidence of instrumentation fracture (i.e., screw breakage, plate fracture, or screw pullout), and/or 3) motion across index level as seen on flexion-extension cervical spine radiographs. Reoperation for adjacent-segment disease was not classified as pseudarthrosis. Patients without reoperation at the index level and patients who did not undergo 1-year postoper- ative imaging were assumed to not have pseudarthrosis. Univariate and multivariate analyses were then performed to identify any independent preoperative or perioperative predictors of pseudarthrosis in this population.

Study data were collected and managed using REDCap (Research Electronic Data Capture) electronic data capture tools hosted at the authors' primary institution. ${ }^{11}$ Categorical variables were summarized with frequency counts and percentages and continuous variables were summarized with means and standard deviations. Pearson's chi-square test and the Student t-test were performed on categorical and continuous variables, respectively, to determine the candidate predictors of pseudarthrosis, which were included in the multivariate logistic regression model. Statistical significance was assessed at an alpha of 0.05 . Data were analyzed using JMP Pro (SAS Institute). This study was approved by the primary institution's review board.

\section{Results}

A total of 326 patients met the inclusion criteria for this study (Fig. 1). Of these, 131 patients underwent ACDF with structural allograft and Osteocel, and 195 patients underwent ACDF with PEEK and Osteocel. Overall, 43 (13.2\%) patients experienced pseudarthrosis and $15(34.9 \%)$ of these patients required revision surgery. The cumulative rate of revision surgery for pseudarthrosis across our entire patient sample was $4.6 \%$. There were no significant differences between patients with and those without pseudarthrosis, respectively, for age (54.1 vs 53.8 years), sex ( $34.9 \%$ vs $47.4 \%$ male), BMI (30.0 vs $\left.29.2 \mathrm{~kg} / \mathrm{m}^{2}\right)$, race, prevalence of prior cervical spine surgery ( $37.2 \%$ vs $33.6 \%$ ), tobacco abuse $(16.3 \%$ vs $14.5 \%)$, chronic kidney disease $(2.3 \%$ vs $2.8 \%)$, and diabetes $(18.6 \%$ vs $14.5 \%)(\mathrm{p}>0.05)$. Univariate analysis did demonstrate that osteopenia or osteoporosis was significantly associated with the development of pseudarthrosis $(16.3 \%$ vs $3.5 \%, \mathrm{p}<0.001)$. Demographic and comorbid data are summarized in Table 1.

A total of $11(8.4 \%)$ patients from the structural allograft group and 32 (16.4\%) patients from the PEEK group developed pseudarthrosis (Figs. 2 and 3). Univariate analysis revealed that compared to structural allograft, the usage of PEEK implant was statistically associated with the development of pseudarthrosis $(\mathrm{p}=0.04)$. Most patients underwent $\mathrm{ACDF}$ with an anterior plate, regardless of implant type, without significant differences in pseudarthrosis rates between patients with and those without an anterior plate $(\mathrm{p}=0.15)$. There was no statistical association between pseudarthrosis and cervical level. Operative data are summarized in Table 2.

Revision surgery for pseudarthrosis most commonly consisted of either repeat ACDF with or without extension to additional levels (66.7\%) or posterior cervical fusion performed with either lateral mass screws or percutaneous facet fusion with DTRAX (Providence Medical Technology) (33.3\%). The average time between index surgery and revision for pseudarthrosis was approximately $18.5 \pm 13.5$ months, and the average follow-up was $23.8 \pm 20.5$ months for patients without pseudarthrosis and $27.6 \pm 19.0$ months for patients with pseudarthrosis. The rates of 30-day readmission for patients with and those without pseudarthro- 


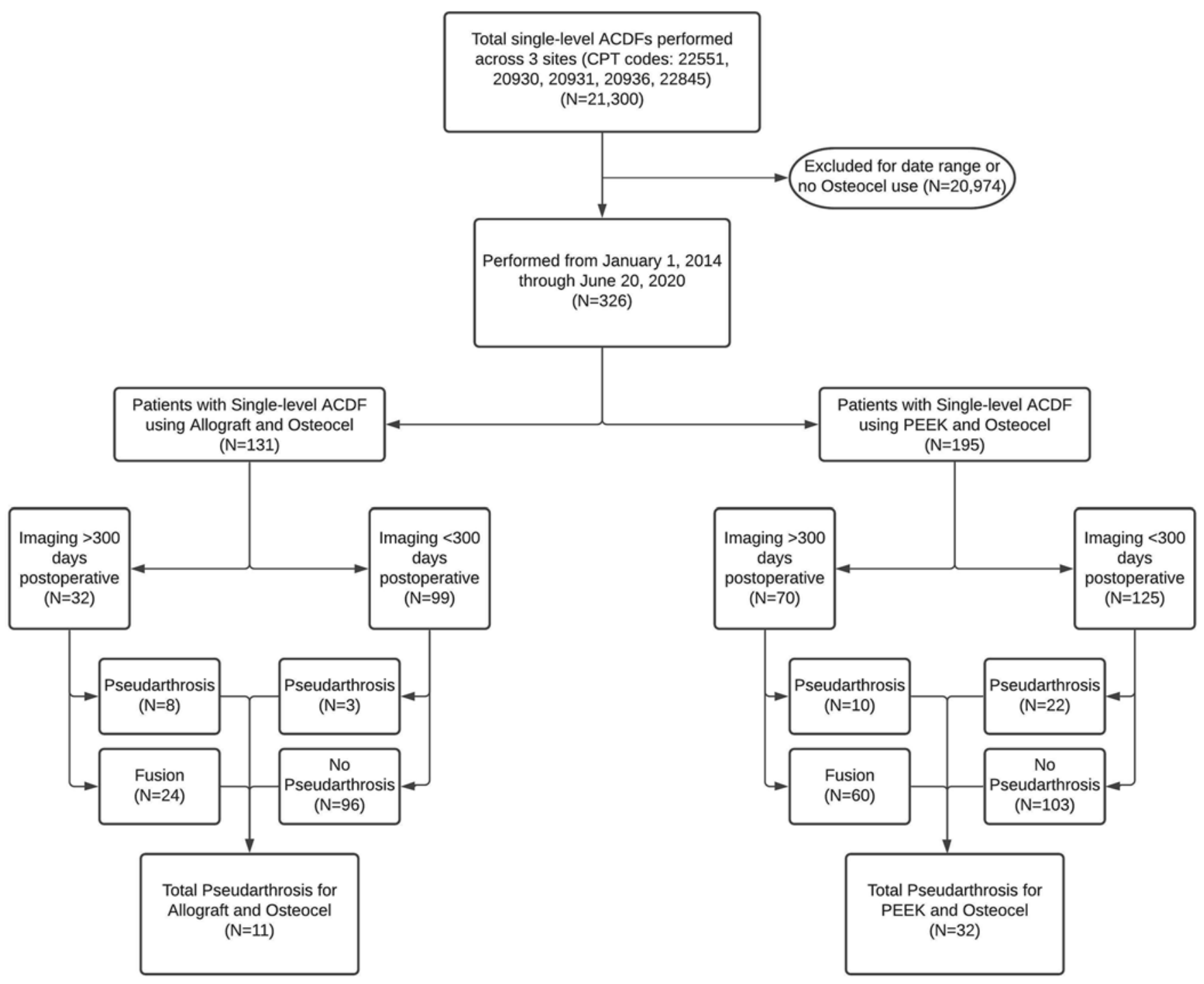

FIG. 1. Patient selection.

sis were statistically similar $(2.33 \%$ vs $1.77 \%, \mathrm{p}=0.80)$ as were the rates of 30-day emergency department visits ( $7.0 \%$ vs $5.3 \%, p=0.65)$, with most visits related to transient dysphagia. Reoperation and complication data are summarized in Table 3.

Age, sex, race, BMI, osteopenia or osteoporosis, and implant type were then included in multivariate analysis. Osteopenia or osteoporosis (OR 4.97, 95\% CI 1.51-16.4, $\mathrm{p}<0.01)$ and usage of PEEK implant (OR 2.24, 95\% CI $1.04-4.83, \mathrm{p}=0.04$ ) were identified as independent predictors of pseudarthrosis. These data are summarized in Table 4. To assess the significance of these variables for predicting pseudarthrosis, we generated a receiver operating characteristic curve and found an area under the curve of 0.72 (95\% CI 0.61-0.77), indicating a good model.

\section{Discussion}

Osteobiologic agents are increasingly being used in spinal fusion to supplement implants and now account for
$17 \%$ or more of all bone graft substitutes used in spine surgery. ${ }^{12}$ Traditional osteobiologics include cancellous allograft and autograft, whereas newer substrates include DBM, bone marrow aspirate, and allograft mesenchymal stem cell matrix. Allograft mesenchymal stem cells (Osteocel) are the newest clinically used osteobiologic. In an industry-sponsored prospective nonrandomized study of patients undergoing ACDF using PEEK and Osteocel, Eastlack et al. found a $92 \%$ rate of bridging bone at 2 years postoperatively, with $95 \%$ of patients exhibiting less than $3^{\circ}$ of motion as seen on dynamic imaging at the fused level. ${ }^{5}$ This study lacked a control group, however, which calls into question the true impact of Osteocel on cervical fusion rates.

In fact, the only non-industry-sponsored study on the usage of Osteocel in the cervical spine was performed in 2016 by McAnany et al. and showed that patients undergoing one- or two-level ACDF with structural allograft and Osteocel experienced a $12.3 \%$ rate of failed fusion at 1 
TABLE 1. Demographics and preoperative characteristics

\begin{tabular}{|c|c|c|c|}
\hline \multirow[b]{2}{*}{ Variable } & \multicolumn{2}{|c|}{ Pseudarthrosis } & \multirow[b]{2}{*}{$\mathrm{p}$ Value } \\
\hline & No $(n=283)$ & Yes $(n=43)$ & \\
\hline Age, yrs & $53.8 \pm 13.9$ & $54.1 \pm 12.1$ & 0.56 \\
\hline Sex & & & 0.13 \\
\hline Male & $134(47.4 \%)$ & $15(34.9 \%)$ & \\
\hline Female & $149(52.7 \%)$ & $28(65.1 \%)$ & \\
\hline Race & & & 0.71 \\
\hline White or Caucasian & $228(80.6 \%)$ & $37(86.1 \%)$ & \\
\hline Black or African American & $44(15.6 \%)$ & $5(11.6 \%)$ & \\
\hline Asian & $2(0.71 \%)$ & $0(0.00 \%)$ & \\
\hline $\begin{array}{l}\text { Native American or } \\
\text { Alaska Native }\end{array}$ & $2(0.71 \%)$ & $1(2.33 \%)$ & \\
\hline$>1$ race & $3(1.06 \%)$ & $0(0.00 \%)$ & \\
\hline Unknown & $4(1.41 \%)$ & $0(0.00 \%)$ & \\
\hline BMI & $29.2 \pm 6.13$ & $30.0 \pm 7.33$ & 0.76 \\
\hline Prior spine surgery & & & 0.12 \\
\hline No & $174(61.5 \%)$ & $21(48.8 \%)$ & \\
\hline Yes & $109(38.5 \%)$ & $22(51.2 \%)$ & \\
\hline Prior cervical spine surgery & & & 0.64 \\
\hline No & $188(66.4 \%)$ & $27(62.8 \%)$ & \\
\hline Yes & $95(33.6 \%)$ & $16(37.2 \%)$ & \\
\hline $\begin{array}{l}\text { Type of prior cervical spine } \\
\text { surgery }\end{array}$ & & & 0.26 \\
\hline Anterior cervical & $90(94.7 \%)$ & $15(93.8 \%)$ & \\
\hline Front-back surgery & $1(1.05 \%)$ & $1(6.25 \%)$ & \\
\hline Posterior cervical & $4(4.21 \%)$ & $0(0.00 \%)$ & \\
\hline Smoking status & & & 0.76 \\
\hline No & $242(85.5 \%)$ & $36(83.7 \%)$ & \\
\hline Yes & $41(14.5 \%)$ & $7(16.3 \%)$ & \\
\hline Chronic kidney disease & & & 0.85 \\
\hline No & $275(97.2 \%)$ & $42(97.7 \%)$ & \\
\hline Yes & $8(2.83 \%)$ & $1(2.33 \%)$ & \\
\hline Diabetes mellitus & & & 0.48 \\
\hline No & $242(85.5 \%)$ & $35(81.4 \%)$ & \\
\hline Yes & $41(14.5 \%)$ & $8(18.6 \%)$ & \\
\hline Osteopenia/osteoporosis & & & $<0.001$ \\
\hline No & $273(96.5 \%)$ & $36(83.7 \%)$ & \\
\hline Yes & $10(3.53 \%)$ & $7(16.3 \%)$ & \\
\hline
\end{tabular}

Values are presented as number (\%) of patients or mean \pm SD unless otherwise indicated. Boldface type indicates statistical significance.

year postoperatively compared to only $5.3 \%$ of patients with structural allograft alone. ${ }^{13}$ There are few other reliable trials focused on the cervical spine that have assessed fusion rates following ACDF using Osteocel. Thus, the utility of Osteocel may not be as definitive as its globally prolific usage would suggest. Given that $1 \mathrm{~mL}$ of Osteocel costs approximately $\$ 460$, understanding its impact on clinical fusion rates is of paramount importance..$^{14}$

The present study, which evaluated 326 patients across 3 tertiary care medical centers and 12 surgeons, is to our knowledge the largest study on fusion rates using Osteocel

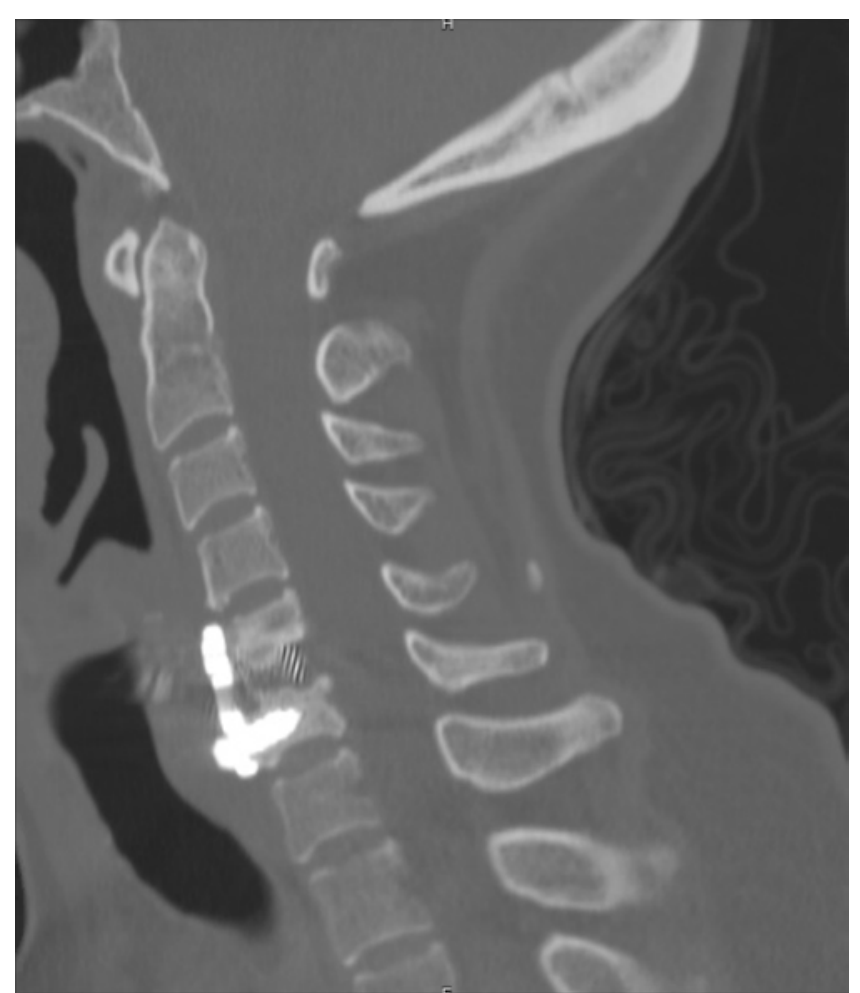

FIG. 2. One-year postoperative CT scan demonstrating pseudarthrosis following C5-6 ACDF with PEEK implant and Osteocel. There is a lack of bridging bone through the disc space, and the right $\mathrm{C} 6$ vertebral screw has retracted by $2 \mathrm{~mm}$. The patient was an otherwise healthy 45-year-old nonsmoking male who went on to have his ACDF revised and extended to $\mathrm{C} 4$ and $\mathrm{C} 7$.

and demonstrates a $13.2 \%$ cumulative rate of pseudarthrosis for a surgical procedure that should have a high success rate (single-level ACDF). When patients were stratified by implant type, patients with structural allograft and Osteocel demonstrated an $8.4 \%$ rate of pseudarthrosis versus a $16.4 \%$ rate seen in patients with PEEK and Osteocel. Multivariate analysis further demonstrated that PEEK was an independent predictor of pseudarthrosis. The rate of pseudarthrosis demonstrated in this study, both cumulatively and stratified by implant type, is higher than that reported in many studies of competing implant technologies. In a 2019 study by Wang et al. of 34 patients undergoing single-level ACDF using either structural allograft or PEEK, the rates of pseudarthrosis at 1 year were $3.4 \%$ and $5.4 \%$, respectively. ${ }^{15}$ In their study, Wang et al. found no difference in fusion rates regardless of the graft material used (local autograft, DBM, or combination of DBM and local autograft)..$^{15}$ A study by Yang et al. of 134 patients undergoing one- or two-level ACDF with either structural allograft or PEEK implants packed with autogenous bone demonstrated 12-month fusion rates of $100 \%$ for both groups, although time to fusion was definitively longer for patients with PEEK cages..$^{16} \mathrm{~A}$ large retrospective analysis of the PearlDiver database by Pirkle et al. demonstrated nonunion rates of only $1.97 \%$ for allograft versus $5.32 \%$ for intervertebral cage devices. ${ }^{17}$ Our study findings are consistent with those of other studies that have reported 

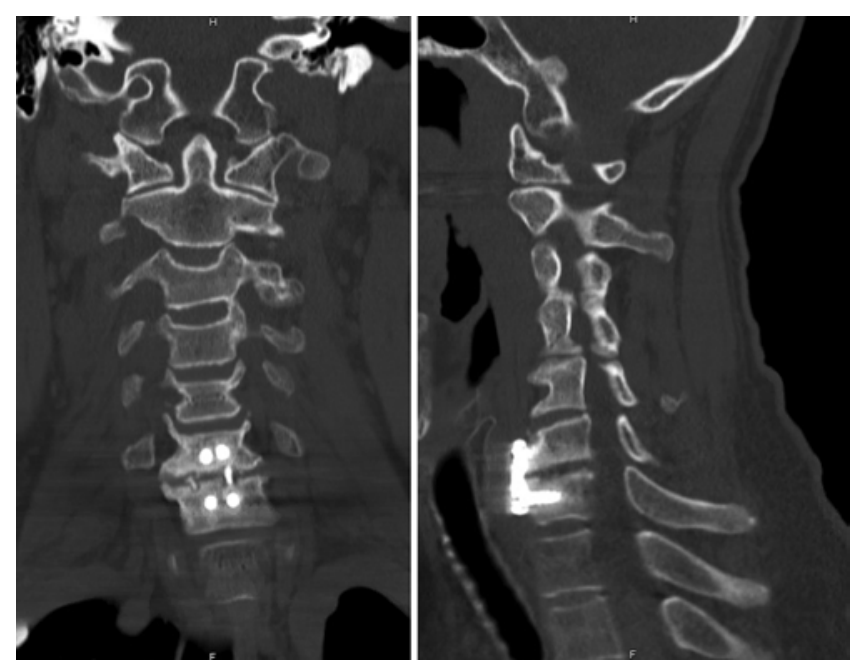

FIG. 3. Eleven-month postoperative CT scans demonstrating pseudarthrosis following C6-7 ACDF with structural allograft and Osteocel. There is a lack of bridging bone throughout the disc space, and there is mild graft subsidence. This patient was an otherwise healthy 57 -year-old nonsmoking male who was able to have his recurrent neck pain managed with conservative therapy.

a higher pseudarthrosis rate for single-level ACDFs when PEEK implants are used. ${ }^{18}$ Recently, there has been emerging literature suggesting an overall underestimation of the rate of pseudarthrosis following single-level fusions..$^{19}$ Lee et al. recently showed a $29.4 \%$ incidence of pseudarthrosis at 1 year following single-level ACDF. ${ }^{20}$ In a study by Crawford et al., this rate was $13 \%$ at the 2-year follow-up. ${ }^{2}$ Large meta-analyses and reviews, however, ${ }^{12}$ suggest that pseudarthrosis rates are still generally less than $10 \%{ }^{21,22}$

Furthermore, the rate of pseudarthrosis in this paper is higher than those reported by competing osteobiologics.

TABLE 2. Operative data

\begin{tabular}{cccc}
\hline & \multicolumn{2}{c}{ Pseudarthrosis } & \\
\cline { 2 - 3 } Variable & No $(\mathrm{n}=283)$ & Yes $(\mathrm{n}=283)$ & p Value \\
\hline Interbody level & & & 0.64 \\
\hline C2-3 & $8(2.83 \%)$ & $0(0.00 \%)$ & \\
\hline C3-4 & $49(17.3 \%)$ & $9(20.9 \%)$ & \\
\hline C4-5 & $35(12.4 \%)$ & $4(9.30 \%)$ & \\
\hline C5-6 & $103(36.4 \%)$ & $13(30.2 \%)$ & \\
\hline C6-7 & $79(27.9 \%)$ & $16(37.2 \%)$ & \\
\hline C7-T1 & $9(3.18 \%)$ & $1(2.33 \%)$ & \\
\hline Interbody type & & & 0.04 \\
\hline Allograft & $120(42.4 \%)$ & $11(25.6 \%)$ & \\
\hline PEEK & $163(57.6 \%)$ & $32(74.4 \%)$ & 0.15 \\
\hline ACDF plate & & & \\
\hline No & $13(4.59 \%)$ & $0(0.00 \%)$ & \\
\hline Yes & $270(95.4 \%)$ & $43(100 \%)$ & \\
\hline Blood loss, $\mathrm{mL}$ & $23.6 \pm 26.8$ & $21.3 \pm 18.7$ & 0.24 \\
\hline
\end{tabular}

Values are presented as number (\%) of patients or mean \pm SD unless otherwise indicated. Boldface type indicates statistical significance.
TABLE 3. Postoperative data

\begin{tabular}{|c|c|c|c|}
\hline \multirow[b]{2}{*}{ Variable } & \multicolumn{2}{|c|}{ Pseudarthrosis } & \multirow[b]{2}{*}{$\mathrm{p}$ Value } \\
\hline & No $(n=283)$ & Yes $(n=43)$ & \\
\hline ACDF revision & & & $<0.0001$ \\
\hline No & $265(93.6 \%)$ & $28(65.1 \%)$ & \\
\hline Yes & & $15(34.9 \%)$ & \\
\hline Type of revision & & & - \\
\hline Anterior cervical & & $10(66.7 \%)$ & \\
\hline Front-back & & $0(0.00 \%)$ & \\
\hline Posterior cervical & & $5(33.3 \%)$ & \\
\hline \multicolumn{4}{|l|}{ Revision level ${ }^{*}$} \\
\hline $\mathrm{C} 2-3$ & & $1(6.67 \%)$ & \\
\hline C3-4 & & $5(33.3 \%)$ & \\
\hline C4-5 & & $8(53.3 \%)$ & \\
\hline C5-6 & & $6(40.0 \%)$ & \\
\hline C6-7 & & $7(46.7 \%)$ & \\
\hline $\mathrm{C} 7-\mathrm{T} 1$ & & $2(13.3 \%)$ & \\
\hline Mos from index op & & $18.5 \pm 13.5$ & \\
\hline Mos to last follow-up & $23.8 \pm 20.5$ & $27.6 \pm 9.0$ & 0.89 \\
\hline Length of stay, days & $1.23 \pm 21.50$ & $1.26(1.14)$ & 0.55 \\
\hline $\begin{array}{l}\text { Complication requiring } \\
\text { admission w/in } 30 \text { days }\end{array}$ & & & 0.80 \\
\hline No & $278(98.2 \%)$ & $42(97.7 \%)$ & \\
\hline Yes & $5(1.77 \%)$ & $1(2.33 \%)$ & \\
\hline ED visit w/in 30 days & & & 0.65 \\
\hline No & $268(94.7 \%)$ & $40(93.0 \%)$ & \\
\hline Yes & $15(5.30 \%)$ & $3(6.98 \%)$ & \\
\hline
\end{tabular}

$E D=$ emergency department.

Values are presented as number (\%) of patients or mean \pm SD unless otherwise indicated. Boldface type indicates statistical significance.

* Multiple levels possible per patient.

In a study of 20 consecutive patients undergoing standalone ACDF with PEEK and DBM, Chung et al. reported a fusion rate of $100 \%$ by 6 months postoperatively. ${ }^{23}$ Another study, by Kim et al., concurrently demonstrated a $100 \%$ fusion rate for patients undergoing single-level ACDF with PEEK cages filled with DBM for patients with subaxial traumatic injuries. ${ }^{24} \mathrm{~A}$ subsequent systematic review of 12 studies utilizing DBM in single- or multilevel ACDF reported a fusion rate of $88.8 \%$ to $100 \%$ at 18 months postoperatively. ${ }^{25}$

TABLE 4. Multivariable analysis of risk of pseudarthrosis

\begin{tabular}{lcr}
\hline \multicolumn{1}{c}{ Variable } & OR $(95 \% \mathrm{Cl})$ & $\mathrm{p}$ Value \\
\hline Age: per yr & $0.99(0.96-1.02)$ & 0.39 \\
\hline Sex: male vs female & $0.71(0.34-1.47)$ & 0.36 \\
\hline Race: Black vs White & $0.85(0.30-2.38)$ & 0.68 \\
\hline BMl: per kg/m² unit & $1.03(0.98-1.08)$ & 0.75 \\
\hline Osteopenia/osteoporosis: yes vs no & $4.97(1.51-16.4)$ & $<0.01$ \\
\hline Interbody type: PEEK vs allograft & $2.24(1.04-4.83)$ & $\mathbf{0 . 0 4}$ \\
\hline
\end{tabular}

Boldface type indicates statistical significance. 
TABLE 5. Fusion rates for common osteobiologics when combined with PEEK or allograft

\begin{tabular}{|c|c|c|c|c|c|c|}
\hline Authors \& Year & $\begin{array}{c}\text { No. of } \\
\text { Patients }\end{array}$ & $\begin{array}{l}\text { No. of } \\
\text { Levels }\end{array}$ & Implant Type & Biologic Type & Fusion Rate & Comments \\
\hline Eastlack et al., $2014^{5}$ & 182 & 249 & PEEK & Osteocel & $92 \%$ & Industry sponsored \\
\hline Chung et al., $2016^{23}$ & 20 & 20 & PEEK & DBM & $100 \%$ & Non-industry sponsored \\
\hline Barber et al., $2018^{28}$ & 92 & 203 & PEEK & Bone marrow & $76.2 \% \mathrm{w} /, 75.6 \%$ w/o bone marrow aspirate & Non-industry sponsored \\
\hline Wang et al., $2020^{15}$ & 168 & 264 & $\begin{array}{l}\text { PEEK \& structural } \\
\text { allograft }\end{array}$ & $\begin{array}{l}\text { DBM, autograft, } \\
\text { or both }\end{array}$ & $\begin{array}{l}1 \text { level: } 95.6 \% \text { PEEK, } 96.6 \% \text { structural } \\
\text { allograft; } 2 \text { levels: } 92.9 \% \text { PEEK, 91.9\% } \\
\text { structural allograft; } \geq 3 \text { levels: } 90 \% \\
\text { PEEK, } 88.9 \% \text { structural allograft }\end{array}$ & Non-industry sponsored \\
\hline Yang et al., $2019^{16}$ & 107 & 134 & $\begin{array}{l}\text { PEEK \& structural } \\
\text { allograft }\end{array}$ & Autograft & $100 \%$ allograft, $100 \%$ PEEK & Non-industry sponsored \\
\hline Chaput et al., $2018^{27}$ & 24 & 31 & Structural allograft & Bone marrow & $86.7 \%$ structural allograft & Non-industry sponsored \\
\hline McAnany et al., $2016^{13}$ & 57 & 85 & Structural allograft & Osteocel & $\begin{array}{l}94.7 \% \text { structural allograft, } 87.7 \% \text { structural } \\
\text { allograft \& Osteocel }\end{array}$ & Non-industry sponsored \\
\hline Lee et al., $2018^{20}$ & 89 & 139 & Structural allograft & None & $91.0 \%$ structural allograft & Non-industry sponsored \\
\hline Crawford et al., $2020^{2}$ & 345 & 345 & Structural allograft & None & $87.0 \%$ structural allograft & Non-industry sponsored \\
\hline
\end{tabular}

Increased rates of fusion have also been observed in constructs containing cancellous allograft. A Liao et al. study on 25 cervical levels demonstrated a fusion rate of $100 \%$ for patients undergoing ACDF with PEEK implants filled with cancellous allograft. ${ }^{26} \mathrm{~A}$ similar study by Vanichkachorn demonstrated a $93.5 \%$ fusion rate at 12 months postoperatively for patients undergoing ACDF with PEEK cages filled with viable cellular bone allograft (Trinity Evolution Musculoskeletal Transplant Foundation). ${ }^{9}$ The sole osteobiologic that has reported higher rates of pseudarthrosis is bone marrow aspirate, which demonstrated fusion rates of $75.6 \%$ and $86.7 \%$ in studies by Chaput et al. ${ }^{27}$ and Barber et al., ${ }^{28}$ respectively. The findings from these studies are summarized in Table 5.

The rate of pseudarthrosis associated with Osteocel, as shown in this study, calls into question its previously reported utility in achieving osseous fusion. Furthermore, at costs of $\$ 460, \$ 2120, \$ 3520$, and $\$ 5400$ for 1-, 5-, 10-, and $15-\mathrm{mL}$ volumes, respectively, Osteocel is considerably more expensive than other common osteobiologics such as cancellous allograft $(\$ 500-\$ 760$ for $10 \mathrm{~mL}) .{ }^{8}$ Use of Osteocel can thus independently add more than $\$ 1000$ to the cost of a single-level ACDF without definitive proof that Osteocel improves fusion past the native properties of the separate implant. The authors thus encourage surgeons to critically review their indications for Osteocel usage in their ACDF population.

Additional considerations regarding associations of the usage of biological agents for bone growth and pseudarthrosis include surgeon-specific factors and surgical technique. In the present study, we sought to increase the generalizability of potential findings by including 12 surgeons across 3 institutions. However, there may have been variations in surgical techniques that resulted in increased pseudarthrosis rates in this study compared to other literature-reported values. Detailed review of individual surgeons' data demonstrated only one surgeon who utilized significant numbers of both structural allograft with Osteocel $(n=125)$ and PEEK with Osteocel $(n=$
77). This surgeon's rate of pseudarthrosis was $5.2 \%(\mathrm{n}=$ 4) for PEEK with Osteocel and $8.0 \%(n=10)$ for structural allograft with Osteocel; the differences in these rates were not statistically significant $(\mathrm{p}>0.05)$. The present study did not include fusion data from other surgeons at the same institutions who used titanium, titanium-coated PEEK, allograft without Osteocel, or autograft. In addition, we also did not compare the current rates of pseudarthrosis to the matched surgeons' previous outcomes from surgeries performed prior to 2014. As such, the rates of pseudarthrosis seen with Osteocel reported in this article cannot be directly compared against a surgeon's historical control group, although the results reported here show the need for these direct comparisons. Our institution is currently initiating the first prospective randomized controlled trial comparing ACDF fusion rates across types of implants and osteobiologics.

This study has additional limitations. As a retrospective review, the inclusion of a comprehensive patient sample was reliant on accurate CPT (Current Procedural Terminology) coding. Additionally, this paper's criteria for pseudarthrosis were more inclusive than those of other studies, which sometimes assign pseudarthrosis only if there is evidence of dynamic motion or instrumentation failure at the operative level(s). Importantly, not all patients included in this cohort underwent postoperative imaging $>300$ days from their index surgery. While the lack of imaging precludes the ability to definitively ascertain the rate of pseudarthrosis within that postoperative period, these patients likely were doing well and without evidence of clinically significant pseudarthrosis. Because our rate of pseudarthrosis is reported with reference to our entire sample size, the rate of pseudarthrosis seen in this paper likely reflects the rate seen among all patients and not the rate seen solely for patients with 1-year postoperative imaging. Last, this study did not include patients with PEEK-only or allograft-only constructs, which would have provided a better direct assessment of Osteocel's effect on fusion potential. Although it is unclear why Osteocel may 
result in a higher rate of pseudarthrosis, the sterilization and immunodepletion process required to prepare Osteocel for human use may remove some of the organic stem cell promotor and bone growth promotor factors that are retained in unprocessed autograft, and this may affect the in vivo survival and differentiation of mesenchymal stem cells as well as their physiological function. ${ }^{29}$ For instance, general sterilization processes can result in a metabolically hypercompetitive environment that further reduces the survival and functionality of the remaining osteoprogenitor cells. ${ }^{30,31}$ Nonetheless, this is the largest non-industryfunded study of fusion rates for patients undergoing ACDF using Osteocel graft substrate.

\section{Conclusions}

The usage of Osteocel in single-level ACDF is associated with a higher rate of pseudarthrosis compared to the literature-reported rates for the usage of alternative osteobiologics. This is especially true when Osteocel is combined with a PEEK implant. In an era of value-based medicine, careful attention should be paid to the cost-benefit profile for novel osteobiologics.

\section{Acknowledgments}

Dr. Goodwin was supported by grants from an NIH/NINDS K12 NRCDP Physician Scientist Award (2K12NS080223-06) and the Robert Wood Johnson Harold Amos Medical Faculty Development Program (RWJ 76238).

\section{References}

1. Bible JE, Kang JD. Anterior cervical discectomy and fusion: surgical indications and outcomes. Semin Spine Surg. 2016; 28(2):80-83.

2. Crawford CH III, Carreon LY, Mummaneni P, et al. Asymptomatic ACDF nonunions underestimate the true prevalence of radiographic pseudarthrosis. Spine (Phila Pa 1976). 2020; 45(13):E776-E780.

3. Guppy KH, Harris J, Paxton LW, et al. Reoperation rates for symptomatic nonunions in anterior cervical fusions from a national spine registry. Spine (Phila Pa 1976). 2015;40(20): 1632-1637.

4. Bishop RC, Moore KA, Hadley MN. Anterior cervical interbody fusion using autogeneic and allogeneic bone graft substrate: a prospective comparative analysis. J Neurosurg. 1996; 85(2):206-210.

5. Eastlack RK, Garfin SR, Brown CR, Meyer SC. Osteocel Plus cellular allograft in anterior cervical discectomy and fusion: evaluation of clinical and radiographic outcomes from a prospective multicenter study. Spine (Phila Pa 1976). 2014; 39(22):E1331-E1337.

6. Burkus JK, Dryer RF, Arnold PM, Foley KT. Clinical and radiographic outcomes in patients undergoing single-level anterior cervical arthrodesis: a prospective trial comparing allograft to a reduced dose of rhBMP-2. Clin Spine Surg. 2017;30(9):E1321-E1332.

7. Cornell CN. Osteobiologics. Bull Hosp Jt Dis. 2004;62(1-2): 13-17.

8. Skovrlj B, Guzman JZ, Al Maaieh M, et al. Cellular bone matrices: viable stem cell-containing bone graft substitutes. Spine J. 2014;14(11):2763-2772.

9. Vanichkachorn J, Peppers T, Bullard D, et al. A prospective clinical and radiographic 12-month outcome study of patients undergoing single-level anterior cervical discectomy and fusion for symptomatic cervical degenerative disc disease utilizing a novel viable allogeneic, cancellous, bone matrix (trinity evolution $^{\mathrm{TM}}$ ) with a comparison to historical controls. Eur Spine J. 2016;25(7):2233-2238.

10. Peppers TA, Bullard DE, Vanichkachorn JS, et al. Prospective clinical and radiographic evaluation of an allogeneic bone matrix containing stem cells (Trinity Evolution ${ }^{\circledR}$ Viable Cellular Bone Matrix) in patients undergoing two-level anterior cervical discectomy and fusion. J Orthop Surg Res. 2017; 12(1):67.

11. Harris PA, Taylor R, Minor BL, et al. The REDCap consortium: building an international community of software platform partners. J Biomed Inform. 2019;95:103208.

12. Grabowski G, Robertson RN. Bone allograft with mesenchymal stem cells: a critical review of the literature. Hard Tissue. 2013;2(2):20.

13. McAnany SJ, Ahn J, Elboghdady IM, et al. Mesenchymal stem cell allograft as a fusion adjunct in one- and two-level anterior cervical discectomy and fusion: a matched cohort analysis. Spine J. 2016;16(2):163-167.

14. Su BW, Vaccaro AR. Point of view. Spine (Phila Pa 1976). 2014;39(22):E1338.

15. Wang M, Chou D, Chang CC, et al. Anterior cervical discectomy and fusion performed using structural allograft or polyetheretherketone: pseudarthrosis and revision surgery rates with minimum 2-year follow-up. J Neurosurg Spine. 2020; 32(4):562-569.

16. Yang S, Yu Y, Liu X, et al. Clinical and radiological results comparison of allograft and polyetheretherketone cage for one to two-level anterior cervical discectomy and fusion: a CONSORT-compliant article. Medicine (Baltimore). 2019; 98(45):e17935.

17. Pirkle S, Kaskovich S, Cook DJ, et al. Cages in ACDF are associated with a higher nonunion rate than allograft: a stratified comparative analysis of 6130 patients. Spine (Phila Pa 1976). 2019;44(6):384-388.

18. Krause KL, Obayashi JT, Bridges KJ, et al. Fivefold higher rate of pseudarthrosis with polyetheretherketone interbody device than with structural allograft used for 1-level anterior cervical discectomy and fusion. J Neurosurg Spine. 2018; 30(1):46-51.

19. Samartzis D, Shen FH, Matthews DK, et al. Comparison of allograft to autograft in multilevel anterior cervical discectomy and fusion with rigid plate fixation. Spine J. 2003;3(6): 451-459.

20. Lee DH, Cho JH, Hwang CJ, et al. What is the fate of pseudarthrosis detected 1 year after anterior cervical discectomy and fusion? Spine (Phila Pa 1976). 2018;43(1):E23-E28.

21. Epstein NE. A review of complication rates for anterior cervical diskectomy and fusion (ACDF). Surg Neurol Int. 2019; 10:100.

22. Shriver MF, Lewis DJ, Kshettry VR, et al. Pseudoarthrosis rates in anterior cervical discectomy and fusion: a metaanalysis. Spine J. 2015;15(9):2016-2027.

23. Chung HJ, Hur JW, Ryu KS, et al. Surgical outcomes of anterior cervical fusion using deminaralized bone matrix as stand-alone graft material: single arm, pilot study. Korean $J$ Spine. 2016;13(3):114-119.

24. Kim SH, Lee JK, Jang JW, et al. Polyetheretherketone cage with demineralized bone matrix can replace iliac crest autografts for anterior cervical discectomy and fusion in subaxial cervical spine injuries. J Korean Neurosurg Soc. 2017;60(2): 211-219.

25. Zadegan SA, Abedi A, Jazayeri SB, et al. Demineralized bone matrix in anterior cervical discectomy and fusion: a systematic review. Eur Spine J. 2017;26(4):958-974.

26. Liao JC, Niu CC, Chen WJ, Chen LH. Polyetheretherketone (PEEK) cage filled with cancellous allograft in anterior cervical discectomy and fusion. Int Orthop. 2008;32(5): 643-648. 
27. Chaput CD, Shar A, Jupiter D, et al. How stem cell composition in bone marrow aspirate relates to clinical outcomes when used for cervical spine fusion. PLoS One. 2018;13(9): e0203714.

28. Barber SM, Radaideh M, Parrish R. Efficacy of autogenous bone marrow aspirate as a fusion-promoting adjunct to anterior cervical discectomy and fusion: a single center retrospective cohort study. Cureus. 2018;10(5):e2636.

29. Salamanna F, Sartori M, Brodano GB, et al. Mesenchymal stem cells for the treatment of spinal arthrodesis: from preclinical research to clinical scenario. Stem Cells Int. 2017; 2017:3537094

30. Rasch A, Naujokat H, Wang F, et al. Evaluation of bone allograft processing methods: impact on decellularization efficacy, biocompatibility and mesenchymal stem cell functionality. PLoS One. 2019;14(6):e0218404.

31. Muschler GF, Nitto H, Matsukura Y, et al. Spine fusion using cell matrix composites enriched in bone marrow-derived cells. Clin Orthop Relat Res. 2003;(407):102-118.

\section{Disclosures}

Dr. Karikari reports being a consultant to and receiving fellowship funding from NuVasive and being a member of the advisory board for the Johnson \& Johnson Adult Deformity Group. Dr. Abd-El-Barr reports being a consultant to Spineology. Dr. Shaffrey reports being a consultant to Biomet, NuVasive, Medtronic, Globus, and SI-BONE; having direct stock ownership in NuVasive; being a patent holder for Medtronic, NuVasive, and Zimmer Biomet; and receiving royalties from Medtronic, NuVasive, and Zimmer Biomet. Dr. Than reports being a consultant for Bioventus and DePuy Synthes and receiving honoraria from LifeNet Health and DJO.

\section{Author Contributions}

Conception and design: Than, Bergin, Wang, Rajkumar, Karikari, Abd-El-Barr, Shaffrey, Yarbrough. Acquisition of data: Than, Bergin, Wang, Park, Rajkumar, Yarbrough. Analysis and interpretation of data: Than, Bergin, Wang, Park, Rajkumar, Goodwin, Karikari, Abd-El-Barr, Shaffrey. Drafting the article: Than, Bergin, Wang, Park. Critically revising the article: Than, Bergin, Wang, Park, Goodwin, Karikari. Reviewed submitted version of manuscript: Than, Bergin, Wang, Park, Goodwin, Karikari, Abd-El-Barr, Shaffrey. Approved the final version of the manuscript on behalf of all authors: Than. Statistical analysis: Than, Bergin, Wang, Park. Administrative/technical/material support: Than, Bergin, Wang, Goodwin, Yarbrough. Study supervision: Than, Bergin, Wang, Shaffrey, Yarbrough.

\section{Correspondence}

Khoi D. Than: Duke University, Durham, NC.khoi.than@ duke.edu. 